\title{
Neighbourhood Initiatives in Wales and England: Shifting Purposes and Changing Scales
}

\author{
Madeleine Pill* \\ Cardiff University
}

\begin{abstract}
Summary
This article compares two government-led 'flagship' area-based initiatives (ABIs) targeting deprived neighbourhoods - the New Deal for Communities, launched in England in 1998, and the Communities First programme, launched in a postdevolutionary Wales in 2001. In England, a shift in the national paradigm from 'big state' interventions towards the 'big society' agenda has heralded the decline of the $\mathrm{ABI}$ approach. In Wales, the approach remains but has recently been re-launched. Shifts in the purpose of neighbourhood governance as encapsulated in these two ABIs are considered and contrasted, using Lowndes and Sullivan's (2008) typology of rationales as a framework. The shift in the emphasis of both ABIs from holistic, placebound strategies to broader, service-influencing efforts points to the up-scaling of neighbourhood governance, despite the renewed policy emphasis on localism.
\end{abstract}

Keywords: Neighbourhood governance; area-based initiatives; Wales; England.

\section{Introduction}

The neighbourhood has received longstanding emphasis as a scale at which to mobilise residents and gain better quality services. This has given rise to a variety of forms of neighbourhood governance. This article focuses on two government-led 'flagship' area-based initiatives (ABIs) targeting deprived neighbourhoods - the New Deal for Communities (NDC), launched in England in 1998, and the Communities First programme, launched in a post-devolutionary Wales in 2001. In England, a shift in the national paradigm from 'big state' interventions towards the 'big society' agenda and the reinvention of 'localism' has heralded the decline of the ABI approach. In Wales, the approach remains but has recently been re-launched. Shifts in the purpose of neighbourhood governance as encapsulated in these two ABIs are considered and contrasted, using Lowndes and Sullivan's (2008) typology of rationales as a framework. 


\section{Neighbourhoods Influencing Services}

Since the 1960s the rhetoric of urban policy has combined the identification of areas for targeted attention with the search for co-ordination in policy and practice (Cochrane, 2007). The neighbourhood has been the focus of successive government-devised ABIs which target additional resources over a specified period of time. While these initiatives have had a range of policy objectives, they have shared the broad aim of ameliorating deprivation through linking residents of the target areas with their service providers to improve service provision.

The neighbourhood has been an attractive locus for intervention. The broad argument is that it is the scale at which many services are delivered and at which a sense of identity can be engendered (Shaw and Robinson, 2010). It is thus posited as the level at which residents can engage, and where their 'expert' knowledge and experience can make an important contribution to policy and practice (Newman et al., 2004: 221). Such initiatives reflect an attempt 'to build on neighbourhood strengths and participation while simultaneously attempting to make government more responsive' (Chaskin and Garg, 1997: 641) by linking residents and service decisions (Lowndes and Sullivan, 2008). In turn, neighbourhood governance, used here to refer to the institutional arrangements that result from these initiatives, is perceived as offering the best opportunity for 'joining up' action. This is by enabling public service providers and the private and voluntary sectors to co-ordinate their work to address local priorities (Foley and Martin, 2000). Overall, the approach draws from the pragmatic view that centralised service provision does not channel resources to deprived neighbourhoods in a way that is suited to their needs.

New Labour's 'turn to community' invigorated these debates by seeking to create conditions in which communities had a stronger role in developing regeneration strategies and monitoring local services (Foley and Martin, 2000: 480). Mechanisms included local participation in service delivery and design under 'Best Value', the creation of Local Strategic Partnerships, and the requirement for Local Area Agreements, under the aegis of a new 'community leadership' role for local government. This seemingly heralded a different approach to deprived neighbourhoods, with the reliance on short-term, targeted ABls (such as the City Challenge and Single Regeneration Budget schemes) replaced by a more 'strategic' approach. Evidence had emerged that ABls were having only limited success in addressing neighbourhood disadvantage (for example, Hall, 1997; and Stewart, 2002); that they displaced rather than resolved problems (Hastings, 2003: 86); and that agencies were potentially being deflected from their mainstream operations. Crucially, it was felt that ABls were masking significant problems regarding the quality and appropriateness of public service provision in disadvantaged neighbourhoods (SEU, 2001).

However, while the practice of 'bending' mainstream spending programmes became a core component of the government's approach to tackling disadvantage and deprivation (Imrie and Raco, 2003: 13), the staple ABI approach to the alleviation of neighbourhood deprivation remained, boosted by a revival of debates about building capacity and social capital in deprived areas (see Taylor, 2007). The 'flagship' initiative was New Deal for Communities (NDC), established in 1998 to produce a local response to five indicators of social deprivation related to mainstream services: unemployment, crime, educational underachievement, poor health, and problems with housing and the physical environment (see for example, Lawless, 2006). It had a total budget of $£ 2$ billion over a ten-year period for programmes in 39 of England's most deprived neighbourhoods (according to central government indices of deprivation), each comprising between one to four thousand households. Each scheme comprised a 
partnership involving residents, community organisations, local authorities and local businesses.

In Wales following devolution, a similar ABI approach was adopted as part of efforts to tackle deprivation. Following a pilot 'People in Communities' initiative in 1999, Communities First, Wales' 'flagship' ABI, was launched by the Welsh Government in 2001. It was also characterised as a response to a perceived failure of grant-aided regeneration programmes to secure sustainable improvements in deprived areas. A central tenet of the initiative was to develop approaches to changing service delivery in deprived communities, drawing on the notion that local people are best placed to understand their needs and, together with local service providers, to consider how services should be changed to make them more effective and efficient (Welsh Government, 2006).

Like NDC, Communities First had an initial ten-year funding commitment. The number of targeted communities was much higher, with an initial 142 areas identified at ward or sub-ward level, mainly according to their levels of deprivation (as per the Welsh Index of Multiple Deprivation). A further 46 areas were added in 2005. Average target population size, at two to four thousand residents, was smaller. The level of resourcing, overall and per scheme, was much lower, at about $£ 45$ million per year shared amongst all the partnerships (compared to each NDC gaining $£ 50$ million for the programme lifetime). Each scheme comprised a partnership supported by a team of community development workers. A 'three-thirds' partnership model was prescribed, comprising the community, the statutory sector and the voluntary and business sectors combined. Similar to NDC, key issues for partnership action related to mainstream services (education, health and well-being, housing and environment, the economy, and community safety) though the theme 'active communities' was also specified given the programme's emphasis on engagement (see, for example, Adamson and Bromiley, 2008).

\section{Research Methods and Data}

The variety of forms of neighbourhood governance and the complexity of their different local and national policy contexts has led to an 'array of different schemas and classifications' (Griggs and Roberts, 2012: 184). The approach here makes use of Lowndes and Sullivan's (2008) typology of rationales for neighbourhood governance (explained below). This, as with other schemas, makes use of 'ideal types'. It is thus open to critique, in particular given the tendency in practice for a mixed approach. Despite this, it is an established analytic framework which has been deployed in a number of studies of neighbourhood governance (see for example, Durose and Lowndes, 2009; Griggs and Roberts, 2012). Scope for its refinement is clear. For example, in their study of neighbourhood working within local authorities - rather than the central government ABIs which form the focus of this research - Griggs and Roberts (2012) augment it with another 'ideal type' schema, Mintzberg's theory of organisations as 'structure in fives'. This enables them to examine the 'institutional hardware' of the 'functional coordination of neighbourhoods within the wider local authority organisational environment' (2012: 187). In turn, in their call for more comparative research, Durose and Lowndes (2010) emphasise the need for a 'dynamic approach' to establish how different rationales co-exist in different contexts, and how such mixes change over time. The research detailed here contributes a partial response to this call. The imperatives accorded to neighbourhood governance, here in the form of ABIs, are inevitably subject to change over time as a result of shifts in the policy context, resulting in a changing balance of emphasis across the initiatives' range of priorities. The methodology used here, which takes a programmatic rather than 
individual initiative view, does not capture the inherent variety as indicated by the sheer number of neighbourhoods engaged across England and Wales. The focus is on the broad changes in emphasis at the programmatic level as a result of policy shifts. While diversity in the purposes accorded to neighbourhood initiatives is evident - and to be expected given the limitations of 'ideal type' schemas - the use of such a framework enables consideration of patterns of divergence or convergence across two national contexts. It is being used to reveal which (combination of) rationales for neighbourhood governance are being privileged, and what this implies about how neighbourhood governance is being used in its broader policy context.

Secondary data sources are primarily used to populate the framework. These include the national evaluation of the now-completed NDC programme (see for example, CLG, 2010; Lawless, 2011a), and evaluations of the ongoing Communities First programme (for example, Welsh Government, 2006; Adamson and Bromiley, 2008; Hincks and Robson, 2010; NAW, 2010). In addition, key policy documentation was reviewed (for example, SEU, 2001; Welsh Government, 2011), as well as academic critiques, which focus on the NDC programme. The methodologies used for the two programmes diverge in that primary data was also gathered from semistructured interviews with Welsh Government and local government officials regarding Communities First. These data were gathered as part of a research project conducted by the researcher for the Welsh Government on neighbourhood working in Wales, and thus cannot be replicated for the NDC programme. The interview data provide additional insights regarding the Welsh $\mathrm{ABI}$, and affect the analysis and conclusions of this comparison by illuminating the priorities pursued in the redesign of the retained programme, in contrast to the now-ended English ABI. The interviews were conducted in 2011, at which time proposals for the future of the programme were out for public consultation. These additional data for Communities First add value to the existing secondary data sources by illuminating the policy context in which the initiative was both able to continue operating (in contrast to the NDC for which the ten-year lifetime stated at its outset was enforced) and the changing imperatives which shape the initiative's relative emphasis upon the purposes of neighbourhood governance. The research approach thus recognises Durose and Lowndes' (2010) call for a 'dynamic approach'. The interviews were conducted during a period of flux and shifting policy priorities, and the insider perspectives they provide illuminate the implications of this changing context upon the initiative. The sample of six respondents was selected in terms of their roles, with officials identified who were considered to occupy positions of importance both regarding the initiative and public service performance which the initiative was seeking to influence.

\section{Purposes of Neighbourhood Governance}

Lowndes and Sullivan's (2008) typology of rationales for neighbourhood governance provides a useful framework for considering and comparing the shifts in the purpose of neighbourhood governance that $\mathrm{ABI}$ s have encapsulated during and after their funding periods. It is used here to frame consideration of the evolution of the NDC and Communities First programmes. Each rationale can be associated with an 'ideal type' of neighbourhood governance which accentuates different purposes or priorities for change: partnership to take a holistic approach to an area (social); management in terms of more effective local service delivery (economic); government through new forms of representation and participation (political); and the empowerment of communities (the civic rationale). The objectives, institutional forms and associated tranche of policy for each rationale are set out in Table 1. 
p. 80. Neighbourhood Initiatives in Wales and England: Shifting Purposes and Changing Scales

Table 1: Purposes of Neighbourhood Governance

\begin{tabular}{|c|c|c|c|c|}
\hline $\begin{array}{l}\text { Neighbourhood } \\
\text { Governance } \\
\text { Ideal Type }\end{array}$ & Rationale & Key objectives & $\begin{array}{l}\text { Institutional } \\
\text { forms }\end{array}$ & Expression in Policy \\
\hline Partnership & Social & $\begin{array}{l}\text { Citizen well-being and } \\
\text { regeneration }\end{array}$ & $\begin{array}{l}\text { Partnership, } \\
\text { management board }\end{array}$ & $\begin{array}{l}\text { ABIs such as New } \\
\text { Deal for } \\
\text { Communities; } \\
\text { Communities First }\end{array}$ \\
\hline Management & Economic & $\begin{array}{l}\text { More efficient and } \\
\text { effective local service } \\
\text { delivery }\end{array}$ & $\begin{array}{l}\text { Contracts, charters, } \\
\text { action plans }\end{array}$ & $\begin{array}{l}\text { Neighbourhood } \\
\text { Management } \\
\text { Pathfinders; } \\
\text { 'neighbourhood } \\
\text { working' }\end{array}$ \\
\hline Government & Political & $\begin{array}{l}\text { Responsive and } \\
\text { accountable decision- } \\
\text { making }\end{array}$ & $\begin{array}{l}\text { Parish/ community } \\
\text { councils }\end{array}$ & 'Double devolution' \\
\hline Empowerment & Civic & $\begin{array}{l}\text { Active citizens and } \\
\text { cohesive communities }\end{array}$ & $\begin{array}{l}\text { Forums, third sector } \\
\text { asset transfer, social } \\
\text { enterprise }\end{array}$ & 'Big Society Localism' \\
\hline
\end{tabular}

Source: adapted from Lowndes and Sullivan (2008: 62)

\section{Neighbourhood Partnership}

The first, partnership, ideal type of neighbourhood governance expresses the intention of bringing together disparate interests in an area in order to co-ordinate activities and address those issues which in the past have proved too difficult (the 'wicked issues') or fallen outside the remit of any one organisation (the 'joining up' of policy). By brokering between competing and possibly factional interests, stakeholders can be persuaded to work together towards collective goals and maximise the use of existing resources (termed 'bending the spend' under New Labour). The two 'flagship' ABls under consideration, certainly at their inception, can be most closely identified with this social rationale.

However, the experiences of the NDC programme illustrate that realisation of partnerships' efforts to influence the mainstream require not only the capacity building of residents to get involved, but also fundamental changes on the part of service providers to engage with residents effectively and to put in place the processes that will make services responsive to them. Analyses found that services' ability to do so was challenged not only by 'bureaucratic resistance to organisational change and resource constraints' (Geddes, 2006: 90) but conflict between national objectives and targets and local priorities. Such 'steering' by government has been subject to much criticism (for example, Geddes, 2006; and Beatty et al, 2010). It was found that the NDC initiatives were driven by a "policy of inclusion but on terms which have already been defined and set outside the community' (Diamond, 2001: 277). Communities were felt to be 'shoehorned' into local policy initiatives according to central government guidelines (Imrie and Raco, 2003: 27).

These findings were supported by Lawless, who in leading the national evaluation team, concluded that 'the NDC programme can be seen as a form of 'locality managerialism' rooted in a centrally imposed framework' (2011a: 530). The evaluation concluded that at best, such an area-based approach can integrate and co-ordinate 
delivery, focus larger agencies and leverage additional resources in order to achieve sustainable change in the longer term. But it also pointed to the limitations of neighbourhood-scale attempts to influence the mainstream as not all policy objectives are appropriate for treatment at this level: 'the services that are delivered best at neighbourhood level are those that interact at that level with service users' (CLG, 2010: 6). The issues most effectively tackled at the neighbourhood level were found to be some aspects of crime, environment, housing management and public health. It is these, and in particular 'crime and grime', which tend to form the focus of initiatives in line with the next ideal type, neighbourhood management.

The challenges of gaining mainstream influence were echoed in Wales. It was assumed that partnerships would determine priorities and influence resource allocation accordingly, with the programme design creating 'clear opportunities for localised influence over 'mainstream' budgets and significant community influence on local decision-making' (Adamson and Bromiley, 2008: 5). However, research has documented the challenge for partnerships in gaining service provider responsiveness. Adamson and Bromiley (2008) concluded that while the programme had promoted the active involvement of residents there was little evidence of community influence over budgets, service delivery, or prioritisation of issues. It was recognised that traditional modes of service operation are not readily responsive, either to 'bottom-up' pressures for community participation or indeed to 'top-down' pressures for service reform (Adamson and Bromiley, 2008: 59). Attempts to ameliorate this led to the creation of an Outcomes Fund in 2007, intended to encourage and enable Communities First partnerships to work more closely with key service providers, from whom match funding was required. This signified a shift in emphasis within the programme from capacity building for community engagement to gaining palpable results, via the partnerships' role as a mechanism to 'bend the spend', and funding incentives to encourage service providers to enable partnerships to do so.

What contrasts in Wales is the relative lack of a national performance framework setting the context for the programme. This was sought, notwithstanding the 'steering' critiques of the NDC programme related to New Labour's 'control freakery'. The programme, a 'practical expression of the principle of putting citizens at the centre of policy delivery' (Adamson and Bromiley, 2008), was subsequently included as one of the drivers for public service improvement in Welsh Government's strategy 'Making the Connections' (Welsh Government, 2004), essentially an attempt at a national policy framework for 'joining up'. But Hincks and Robson's (2010) subsequent evaluation, as with the NDC evaluation, highlighted limitations on the scope of neighbourhood-scale programmatic interventions to deliver the wider outcomes needed to tackle deprivation. The ongoing need for such spatial targeting to link with wider policy agendas, objectives and funding streams was emphasised (Hincks and Robson, 2010: 29). As a Welsh government respondent commented, 'we need to get partnerships to be able to set what they're trying to do in that bigger strategic context'.

The political pressure increased with a review undertaken by the National Assembly's Public Accounts Committee, which found that the 'programme has not delivered good value for the significant amount of public money spent on it' and concluded that 'we are particularly concerned that the Welsh Government provides insufficient direction to service providers and is not adequately monitoring the programme' (NAW, 2010: 8).

As the future of the programme was being considered, a Welsh government respondent framed the partnerships as a mode of delivery for services, 'an absolutely fundamental infrastructure that allows you to deliver a whole load of stuff'. But for effective community engagement in service influencing, this infrastructure has to be coupled with development of joint ways of working and inter-scalar modes for doing so. 


\section{Neighbourhood Management}

This ideal type stresses the importance of re-ordering and combining local services in accordance with an agreed strategy to meet the needs of a particular area. It has an economic rather than social rationale because it seeks to enable more efficient and effective service delivery. It 'empowers front-line managers, enabling them to respond to citizens' needs and so improve allocative efficiency by 'joining-up' separate services' (Lowndes and Sullivan 2008: 66). In contrast with the more holistic ambitions of neighbourhood partnership, this form focuses on services with the best 'fit' at neighbourhood level, in particular 'crime and grime', housing and public health. It is best encapsulated in England's now-defunct Neighbourhood Management Pathfinder (NMP) programme, which funded the dedicated officer teams and facilitation of community engagement regarded as essential ingredients of the process in 35 target areas (for the evaluation, see SQW Consulting, 2008). But this form of neighbourhood governance was also a part of the NDC approach, given its emphasis on working with the mainstream regarding the outcomes intended to improve 'places' (Lawless, 2011a: 521). The service-influencing nature of the approach also made it attractive for inclusion in NDC 'forward strategies'. This was because it was perceived as a way of enabling continuance of neighbourhood targeting in the absence of initiative funding, even though in its pure form this approach requires neighbourhood-based staff.

Other, more generic, 'neighbourhood working' approaches, which may lack dedicated, area-based staff teams, are also in evidence. These can be characterised as local government attempts to 'reach down' to 'neighbourhoods' (at a larger scale than that targeted by ABIs, often comprising clusters of wards), to gauge resident priorities regarding service provision. These may be local government-wide systems, rather than ones focused on deprived neighbourhoods (and as such have commonalities with the next ideal type, neighbourhood government). For example, Bristol has created fourteen 'neighbourhood partnerships', each covering two to three council wards of up to 30,000 people, with the aim of influencing the way public services are delivered (Bristol City Council, 2008: 4). Towards the end of its funding period, Bristol's NDC was tasked by the council with rolling out such 'neighbourhood working' for the broader neighbourhood partnership area in which it was contained (see Davies and Pill, 2011 and 2012). The NDC's forward strategy (as set out in the CaH Revised Strategic Plan, 2005) was to pursue a neighbourhood management model until 2013 , with a small staff team funded by income streams generated by the minor asset portfolio it had developed during the programme lifetime. This shift from community-led regeneration to community-influenced neighbourhood service delivery represented a shift, with the end of $A B I$ funding, from neighbourhood partnership to management approaches.

This management form of neighbourhood governance has more commonality with Communities First than NDC, in part because the Welsh programme lacked the funding levels to enable the partnerships to engage in other endeavours such as capital projects. This is illustrated by the commonalities between the Communities First and NMP models, for example with regard to community action planning. Community First's emphasis was on getting communities engaged in influencing services, initially by (as explained by a Welsh government respondent), "creating a community which you can then engage with'. Latterly, and in the programme's re-launch in 2012, the emphasis is upon place-based service-influencing, despite the programme facing the difficulties typically faced by a time-limited $\mathrm{ABI}$ in gaining influence over service providers. A Welsh Government respondent stressed the partnerships' role as a community-based infrastructure which provides 'that softer information' to service providers: 
p. 83. Neighbourhood Initiatives in Wales and England: Shifting Purposes and Changing Scales

There's an upfront cost in establishing these things but the long-term benefits are that people's voice is heard and understood, and either something's done about it, or they're given a reason about why that can't be done.

That the Communities First programme draws most on the economic rationale of neighbourhood management (rather than the social rationale of partnership) is illustrated by the comment of another government respondent:

You create neighbourhoods to maximise your service delivery, and I think if you've got good information, and the service providers actually work together, and exchange information, you can really make a difference to people's experience of public services and a difference in the cost of providing things.

This shift in rationales is also evident in the design of the new programme (Welsh Government, 2011). Its target areas, or 'clusters', sought in the new guidance have extended boundaries with a much greater target population of 10-15,000 residents. While still focused on the most deprived ten per cent of areas, clusters can include areas in the 30 per cent most deprived if, for example, these are adjacent to the poorest areas and fall within the same boundary for a 'key partner service'. Such rescaling is seen as creating a 'workable size', enabling better interaction with service providers as a result of better boundary alignment. During the consultation period on the new programme, one government respondent commented:

One of the obstacles that has hindered the effectiveness of the partnerships has been the sheer number of partnerships and the scale at which they operate... working at a slightly bigger scale certainly has a lot of advantages in terms of critical mass and effective use of resources.

Another explained:

If you changed [Communities First co-ordinators] mindset around to pulling together all the information on the wider service requirements of a bigger [geographical] chunk, your information would make better investment decisions coming down to your community.

\section{Neighbourhood Government}

This ideal type reflects the political priorities of working at the sub-local level, seen as correcting the perceived failings in the democratic accountability of local government. New Labour's 'double devolution' agenda, which sought some delegation of powers from central to local government, and then from local government to neighbourhoods (Smith et al., 2007), is most closely linked to this rationale. Powers were devolved to local government in England to be able to create governance structures such as community or parish councils through a 'community governance review' process. By definition, this ideal type is the one least represented in the ABls such as NDC and Communities First, though there are commonalities with ABls engaging in broader, sublocal authority-wide systems of neighbourhood working, as was the case with Bristol's NDC (above). 


\section{Neighbourhood Empowerment}

The fourth, empowerment, ideal type of neighbourhood governance describes active citizens who willingly participate in community affairs and local decision-making and work together to attain an improved quality-of-life in the area. An increasing stress on this civic rationale is evident in successive ABls prior to the NDC in terms of encouraging neighbourhood-level ownership of problems and of attempts to resolve these. Under NDC, a significant level of resources was devoted to community engagement and capacity building. The programme sought to 'build the capacity' of communities not only to engage (in partnerships which express the social rationale) but to provide them with 'the skills and knowledge to become active in eradicating [their] deprivation' (Imrie and Raco, 2003: 21), empowering them in line with the civic rationale.

In England, this policy emphasis on the 'self-management and responsibilisation' of communities (Cochrane, 2007: 52) has now culminated in the 'big society' agenda. 'Localism' is the term being applied to a wide range of strategies emphasising devolving power down the hierarchy. These include community-based organisations taking over assets from public bodies which are then managed in the interests of the local community as an expression of community 'self-help'. This has been reflected in the organisational structures established by NDC initiatives as part of their forward strategies. Many have become community development trusts or social enterprises, in some cases such as Bristol's NDC deriving some income from capital assets acquired during the main funding period. Strategies also include seeking to transfer responsibilities for services to local communities and intermediate third sector agencies. Such direct service provision contrasts with the neighbourhood partnership and management mode of engaging communities in seeking to influence service providers.

Overall, the big society agenda has heralded the decline of central government-led ABls such as NDC in England and a fundamental shift away from redistribution towards a philosophy of self-help (Bailey and Pill, 2011: 940). The agenda has been subject to much criticism on philosophical, political, and practical grounds (see for example Kisby, 2010 and Bartels et al., 2011), not least due to its lack of emphasis on inequality and deprivation. While the NDC programme has left a substantial legacy of communityowned assets and infrastructure in line with the big society's self-help ethos, this is a poor substitute for the substantive public investment funnelled through the programme, which also gave initiatives some power to influence. In turn, the NDC experience strongly suggests there is not sufficient capacity within deprived communities for them to 'take over' public services' (Lawless, 2011b: 61). Drawing from the national NDC evaluation, Lawless expresses further reservations regarding community-level understanding about 'the scale of, and appropriate policies through which to moderate, local problems' (2011b: 55) and the ability of delivery agencies to respond to 'what is likely to prove a myriad of ill-conceived ideas when their own resources are being cut' (2011b: 61). Thus while empowerment is stressed in big society policy rhetoric, in practice it does not seem to offer a credible way forward in terms of tackling deprivation at the neighbourhood level (Davies and Pill, 2012: 199).

In Wales, the Communities First programme was seen as creating 'a potential for community empowerment throughout the policy framework' (Adamson and Bromiley, 2008). However, the notion of empowerment used here differs from that of self-help. As explained above, the programme best reflects the neighbourhood governance ideal types of partnership and management, and emphasis on the place-based serviceinfluencing of the latter is paramount in the programme's re-launch. As a Welsh 
government respondent commented, 'unless we have willing partners [in Communities First], especially in these straightened times, it won't work, that's the reality'.

Despite this, some Communities First partnerships are pursuing social enterprise endeavours, with the aim of becoming self-sustaining (and thus safe from the vagaries of programmatic funding). An official explained the intention that one local authority's four partnerships will become Community Regeneration Trusts, seen as 'a model of social enterprise independence'. However, respondents stressed that Communities First partnerships should concentrate on service influencing and co-ordination rather than direct service delivery. If partnerships are able to develop and deliver projects, perhaps via affiliated social enterprises, that is to be welcomed, but the main emphasis should be on gaining responsive service delivery:

Partnerships need to start by saying it's about facilitating working between the service deliverers, not about creating more service delivery agencies. There may well in all communities be gaps in service delivery that could be usefully filled, by creating the right new mechanisms [such as social enterprises], but let's not make that the be all and end all, in a way that undermines the principle.

In Wales, the English big society agenda has not been adopted, with Carl Sargeant, Minister for Social Justice and Local Government stating:

Putting people and communities at the heart of public services is at the core of our programme for public service improvement, and it always has been.... Communities First engages and empowers communities to find long-term solutions. This is a prime example of how Wales has harnessed the powers of its own big society (NAW, 2011).

But the form taken by the re-launched programme illustrates that Wales, while retaining a politically palatable $A B I$ approach (with a slightly reduced budget of $£ 40$ million per year), has had to increase the size of the target areas in the hope that, as a local government officer explained, "the benefit of having that wider approach will outweigh any dilution'. Whatever the response is called, both countries share the context of recession and deficit-reducing severe cuts in public expenditure.

\section{Changing Purposes}

As has been demonstrated, the rationales identified for the neighbourhood as a scale for intervention and action (Lowndes and Sullivan, 2008) are not mutually exclusive and elements of three of the four rationales are readily identifiable within both the NDC and Communities First programmes. In terms of the typology, the NDC can be most closely associated with the partnership form of neighbourhood governance, as well as drawing upon the management form. An increasing stress on the empowerment form is also now starkly evident. In Communities First, the shift from an emphasis on partnership to management can also be discerned. The programme's continued use of the notion of 'empowerment' relates to influencing mainstream service delivery rather than engaging in self-help behaviours, an emphasis reaffirmed in the programme's relaunch in 2012.

These findings illustrate that the purposes accorded to neighbourhood governance are subject to change over time due to their shifting policy and financial context, exacerbated given central government's hand in the instigation and operation of neighbourhood-targeted initiatives, and latterly, in England at least, in their abandonment. Such endeavours are inherently political and face the challenges of 
continuation of their purpose once their funding term has ended. This is particularly ironic in the context of initiatives' emphasis on securing community influence on service provision. This is illustrated by the Neighbourhood Management Pathfinders, which sought to embed the neighbourhood management approach by fundamentally, and permanently, changing the relationships between the target communities and their service providers. But as a time-limited $A B I$ the approach was vulnerable to being perceived as gaining 'special' resource separate from the 'mainstream' which it sought to both become a part of and influence (see Pill and Bailey, 2012: 16). Overall, the neighbourhood governance infrastructure that ABls constitute faces the risk of being relatively easily separated from 'normal', mainstream service delivery when the special resource which may have attracted service provider partner engagement ends, despite efforts to develop performance frameworks which seek to align the outcomes sought by neighbourhoods and service providers.

The shift in the emphasis of both ABls under consideration here from partnership to management, that is, from holistic, place-bound strategies to broader, serviceinfluencing efforts without the level of resource, also points to the rescaling of neighbourhood governance, despite the renewed policy emphasis on localism. For example, with the end of the NDC and other neighbourhood-targeted programmes in Bristol, the apparatus of neighbourhood governance was up-scaled, moving away from bespoke neighbourhood programmes towards a more centralised model with fewer resources. This highlights that the commitment to resourcing neighbourhood governance initiatives was on the wane under New Labour, before the advent of the big society's self-help ethos (Davies and Pill, 2012). In their study of neighbourhood working in 15 English local authorities, Griggs and Roberts (2012) also found a privileging of neighbourhood management approaches. They warn that, while understandably appealing to local politicians and officials, this emphasis is rife with tensions between empowerment and management, running the risk of surfacing the incapacity of local authorities to respond to local community expectations and grievances' (2012: 183). They characterise neighbourhood management as a neoliberal 'roll-out' strategy, whereby its focus on the community's role in improving public services seeks to 'constrain and accommodate the demands of those marginalised by marketisation and individualisation' (2012: 185).

Such up-scaling of targeted efforts to tackle deprivation is also evident in the redesign of the Communities First programme. The programme's target areas, or 'clusters', are now much larger in size at 10-15,000 residents rather than the two to four thousand residents of the programme's first incarnation. Funding for former, smaller-scale partnerships which do not become part of a new cluster will end.

\section{Conclusions}

Welsh policy can be said to have tracked (New Labour's) English approaches in terms of the development of its flagship $\mathrm{ABI}$, and its still-emergent public service performance framework. But now divergence is evident, with English coalition government abandonment of the ABI approach to neighbourhood governance and dismantling of its performance frameworks (as provided through the Audit Commission and national indicators). This can be related to ideological as well as economic imperatives for deficit reduction, but it has been seen that neighbourhood governance was already on the wane in the later stages of New Labour's tenure. Welsh retention of this model, with the re-launched Communities First programme (now described as a "community focussed anti-poverty programme'), reflects a continued political commitment to 'joining up' to tackle deprivation. The intent to 'mainstream' Communities First is reflected in the new programme's development of an Outcomes Framework, through 
which partnerships are expected to relate their achievements to the outcomes sought by service providers and government, and its 'Regional Framework', based on the six regions developed for broader public service collaboration (Welsh Government, 2011). Such changes were politically necessary in light of the demands of the National Assembly's Public Accounts Committee (NAW, 2010).

However, the up-scaling, or 'hollowing out' (Davies and Pill, 2011) of neighbourhood governance in England is also evident in Wales. This points to the normative appeal of service-influencing neighbourhood management approaches, politically expedient in the face of drastic public sector funding cuts. But such amalgamation of target areas to provide the 'best fit' for service providers hinders neighbourhood-specific responses. While $\mathrm{ABI}$ regimes have been much critiqued for focussing on 'palliative measures rather than on the underlying structural causes of deprivation' (Foley and Martin, 2000: 486 ), the value of the neighbourhood as a site and scale for innovation remains. As Lawless (2011a: 530) explains, the NDC was not intended to address wider structural forces, but to act as a laboratory for 'holistic, place-bound, strategies'. The paradox is that despite increasing emphasis on localism, community empowerment and civil renewal, initiatives at the neighbourhood scale are not a viable approach in an era of economic austerity and deficit reduction.

\section{Acknowledgements}

This article draws from a research project funded by the Welsh Government's New Ideas Social Research Fund in 2010-2011. Many thanks to all those who participated.

* Correspondence address: Madeleine Pill, Cardiff University, School of City and Regional Planning, Glamorgan Building, Cardiff, CF10 3WA. Email: pillmc@cardiff.ac.uk.

\section{References}

Adamson, D. and Bromiley, R. (2008) Community Empowerment in Practice: Lessons from Communities First. York: Joseph Rowntree Foundation.

Bailey, N. and Pill, M.C. (2011) The Continuing Popularity of the Neighbourhood and Neighbourhood Governance in the Transition from the 'Big State' to the 'Big Society' Paradigm. Environment and Planning C: Government and Policy, 29, 5, 927-942.

Bartels, K., Cozzi, G. and Mantovan, N. (2011) Public spending and volunteering: 'the big society', crowding out, and volunteering capital. http://mpra.ub.uniuenchen.de/29730/1/MPRA paper 29730.pdf

Beatty, C., Foden, M., Lawless, P. and Wilson, I. (2010) Area-based regeneration partnerships and the role of central government: the New Deal for Communities programme in England. Policy and Politics, 38, 2, 235-251.

Bristol City Council (2008) Corporate Plan 2008-2011. Bristol: Bristol City Council.

CaH, Community at Heart. (2005) Revised Strategic Plan 2005-2010. Bristol: CaH.

Chaskin, R. J. and Garg, S. (1997) The Issue of Governance in Neighbourhood-Based Initiatives. Urban Affairs Review, 32, 5, 631-661.

CLG (Department for Communities and Local Government) (2010) The New Deal for Communities Programme: Achieving a Neighbourhood Focus for Regeneration. The NDC National Evaluation: Final Report Volume 1. London: CLG. 
p. 88. Neighbourhood Initiatives in Wales and England: Shifting Purposes and Changing Scales

Cochrane, A. (2007) Understanding Urban Policy: A Critical Approach. Oxford: Oxford University Press.

Davies, J.S. and Pill, M.C. (2011) Hollowing-out Neighbourhood Governance? Re-scaling Revitalization in Baltimore and Bristol. Urban Studies, DOI: 10.1177/0042098011422576. Published online before print: http://usj.sagepub.com/content/early/2011/11/10/0042098011422576

Davies, J.S and Pill, M.C. (2012) Empowerment or Abandonment? Prospects for Neighbourhood Revitalization under the Big Society. Public Money and Management, 32, 3, 193-200.

Diamond, J. (2001) Managing change or coping with conflict? Mapping the experience of a local regeneration partnership. Local Economy, 16, 4, 272-285.

Durose, C. and Lowndes, V. (2010) Neighbourhood Governance: Contested Rationales within a Multi-Level Setting - A Study of Manchester. Local Government Studies, 36, 3, 341-359.

Foley, P. and Martin, S. (2000) A new deal for the community? Public participation in regeneration and local service delivery. Policy \& Politics, 28, 4, 479-492.

Geddes, M. (2006) Partnership and the limits to local governance in England: Institutionalist analysis and neoliberalism. International Journal of Urban and Regional Research, 30, 1, 76-97.

Griggs, S. and Roberts, M. (2012) From Neighbourhood Governance to Neighbourhood Management: A 'Roll-Out' Neo-Liberal Design for Devolved Governance in the United Kingdom? Local Government Studies 38, 2, 183-210.

Hall, P. (1997) Regeneration policies for peripheral housing estates: inward- and outward-looking approaches, Urban Studies, 34, 5-6, 873-90.

Hastings, A. (2003), Strategic, multi-level neighbourhood regeneration: an outwardlooking approach at last? in: R. Imrie and M. Raco, Urban Renaissance? New Labour, Community and Urban Policy. Bristol: The Policy Press.

Hincks, S. and Robson, B. (2010) Regenerating Communities First Neighbourhoods in Wales. York: Joseph Rowntree Foundation.

Imrie, R and Raco, M. (2003) Community and the changing nature of urban policy, in: R. Imrie and M. Raco, Urban Renaissance? New Labour, Community and Urban Policy. Bristol: The Policy Press.

Kisby, B. (2010) The big society: power to the people? Political Quarterly, 81, 4, 484491.

Lawless, P. (2006) Area-based urban interventions: Rationale and Outcomes: the New Deal for Communities Programme in England. Urban Studies, 43, 11, 1991-2011.

Lawless, P. (2011a) Understanding the scale and nature of outcome change in arearegeneration programmes: evidence from the New Deal for Communities programme in England. Environment and Planning C: Government and Policy, 29, 3, 520-532.

Lawless, P. (2011b) Big Society and community: lessons from the 1998-2011 New Deal for Communities Programme in England. People, Place and Policy Online, 5, 2, 55-64.

Lowndes, V. and Sullivan, H. (2008) How low can you go? Rationales and Challenges for Neighbourhood Governance. Public Administration, 86, 1, 53-74.

NAW, National Assembly for Wales. (2010) Public Accounts Committee: Communities First. Cardiff: NAW.

NAW, National Assembly for Wales. (2011) Record of Proceedings, 2 February 2011:

http://www.assemblywales.org/bus-home/bus-third-assembly/bus-chamber/buschamber-third-assembly-rop.htm?act=dis\&id=209214\&ds=3/2011

Newman, J., Barnes, M., Sullivan, H. and Knops, A. (2004) Public Participation and Collaborative Governance. Journal of Social Policy, 33, 2, 203-223.

Pill, M.C. and Bailey, N. (2012) Community Empowerment or a Strategy of Containment? Evaluating Neighbourhood Governance in the City of Westminster. 
Local Government Studies. DOI:10.1080/03003930.2012.679934. Published online before print: http://dx.doi.org/10.1080/03003930.2012.679934

SEU, Social Exclusion Unit (2001) A New Commitment to Neighbourhood Renewal: National Strategy Action Plan. London: Cabinet Office.

Shaw, K. and Robinson, F. (2010) UK urban regeneration policies in the early twentyfirst century: continuity or change? Town Planning Review, 81, 2, 123-149.

Smith, I., Lepine, E. and Taylor, M. (eds). (2007). Disadvantaged by where you live? Neighbourhood governance in contemporary urban policy. Bristol: The Policy Press.

Stewart, M. (2002) Collaboration and co-ordination in area-based initiatives. Research Summary No.1. London: Neighbourhood Renewal Unit and Regional Coordination Unit.

SQW Consulting (2008) Neighbourhood Management Pathfinders: Final Evaluation Report. London: Communities and Local Government.

Taylor, M. (2007) Neighbourhood Management and Social Capital. London: Communities and Local Government.

Welsh Government. (2004) Making the Connections: Delivering Better Services for Wales. Cardiff: Welsh Government.

Welsh Government. (2006) Interim Evaluation of Communities First: Final report. Cardiff: Welsh Government.

Welsh Government. (2011) Summary of Ministerial Decisions regarding Communities First from April 2012: http://wales.gov.uk/docs/dsjlg/publications/comm/111221cfsummaryen.pdf 